\section{Radio-activity and Atomic Numbers.}

LET $T h_{\mathrm{T}}, \mathrm{Ra}_{\mathrm{T}}, \mathrm{Ac}_{\mathrm{T}}$ be the periods of half-change of corresponding members of the thorium, radium, and actinium family respectively, $M$ the atomic number, $\mathrm{M}(\mathrm{Pb})$ that of the lead-group, and $c$ a constant $( \pm 4.5)$; then for all substances emitting a rays-

$$
T h_{\mathrm{T}}=\sqrt{\mathrm{Ra}_{\mathrm{T}} \cdot \mathrm{Ac}_{\mathrm{T}} / \mathrm{C}^{\mathrm{Mi} \cdots \mathrm{M}(\mathrm{Pb})}}
$$

For analogous $\beta$-radiators $\mathrm{Ra}_{\mathrm{T}} \cdot \mathrm{Ac}_{\mathrm{T}} / \mathrm{Th}^{2}{ }_{\mathrm{T}}$, though not unity for group B IV. is $>_{I}$ for B III., and $<_{I}$ for B V. (the only three groups in which comparable values are known).

The only exception here, as in all similar relations, is thorium-X (or actinium-X). For radiothorium, where a few months as well as two years are given for the period of half-change, the formula gives the first value. Of course, very accurate results cannot be expected from values like $2 \mathrm{~min}$., $3 \mathrm{~min}$., $0.002 \mathrm{sec}$, etc., but the differences are nowhere greater than what from this lack of precision must be expected.

\begin{tabular}{|c|c|c|c|c|c|}
\hline $\begin{array}{l}\text { Radiothorium } \\
\text { Thorium eman } \\
\text { Thorium A... } \\
\text { Thorium } C_{1}^{a}\end{array}$ & $\begin{array}{l}\ldots \\
\ldots \\
\ldots \\
\cdots\end{array}$ & $\begin{array}{c} \\
\cdots \\
\cdots \\
\cdots \\
\cdots\end{array}$ & 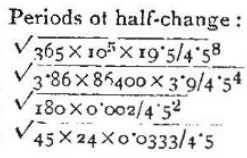 & $\begin{array}{l}\text { Calculated } \\
d=65 \text { days } \\
s=56.4 \mathrm{sec} . \\
s=0 .{ }_{34} \mathrm{sec} . \\
h=2 \cdot 83 \text { bours }\end{array}$ & $\begin{array}{l}\text { Experimental } \\
\text { A few months } \\
53 \mathrm{sec} \text {. } \\
0.14 \mathrm{sec} \text {. } \\
2.87 \text { hours }\end{array}$ \\
\hline $\begin{array}{l}\text { Ionium... ... } \\
\text { Radium emana } \\
\text { Radium A ... } \\
\text { Radium } C_{1}^{a} \cdots\end{array}$ & $\begin{array}{l}\ldots \\
\text { ation } \\
\ldots \\
\ldots\end{array}$ & $\begin{array}{l}\ldots \\
\ldots\end{array}$ & 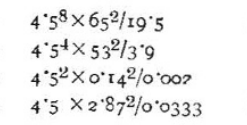 & $\begin{aligned} d & =\mathrm{ro}^{5} \text { years } \\
s & =3^{\circ} 4^{2} \text { days } \\
s & =33^{\circ} 31 \text { min. } \\
h & =46^{\circ} .4 \text { days }\end{aligned}$ & $\begin{array}{l}10^{5} \text { years } \\
3.86 \text { days } \\
3 \text { min. } \\
45 \text { days }\end{array}$ \\
\hline $\begin{array}{l}\text { Radio-actinium } \\
\text { Actinium eman } \\
\text { Actinium A... } \\
\text { Actinium } \mathrm{C}_{2} \\
\text { Actinium } \mathrm{C}_{1}^{\alpha}\end{array}$ & $\begin{array}{l}\text { nation } \\
\ldots \\
\ldots \\
\ldots\end{array}$ & $\begin{array}{l}\cdots \\
\ldots \\
\cdots\end{array}$ & $\begin{array}{l}4 \cdot 5^{8} \times 65^{2} / 3^{6} 5 \times 10^{5} \\
45^{4} \times 53^{2 / 3} \cdot 84 \times 86400 \\
4 \cdot 5^{2} \times 0.14^{2} / 180 \\
45^{2} \times 10^{-22} / 10^{-6} \\
4 \cdot 5 \times 2 \cdot 87^{2} / 45 \times 24\end{array}$ & $\begin{aligned} d & =19^{\circ} 5 \text { days } \\
s & =3.5 \mathrm{sec} . \\
s & =0.0022 \mathrm{sec} . \\
s & =2 \cdot 10^{-15} \mathrm{sec} . \\
m & =2.03 \mathrm{~min} .\end{aligned}$ & $\begin{array}{l}19^{\circ} 5 \text { days } \\
3.9 \text { sec. } \\
0^{\circ} 002 \text { sec. } \\
? \\
2 \mathrm{~min} .\end{array}$ \\
\hline
\end{tabular}

Gorsel, Holland, June 26.

A. VAN DEN BROEK.

\section{Seeing and Photographing Very Faintly Illuminated Objects.}

THE question frequently arises, particularly among astronomers, whether it is possible to photograph apparatus), at the other end of which a 6 inch $\mathrm{F} / 53$ telescope objective formed an image on the plate tested, or, with an ocular, on the retina.

The results obtained are tabulated below :-

Int. at source On plate On retina Min.exp. Vision (I) 8.6 m.c. 0.24 m.c. 0.69 m.c. 16 sec. Comportable (2) $0.330 .00920 .026 \quad 7 \mathrm{~min}$. Distinct, un. (3) $0.01270 .000350 .001023 \mathrm{hr}$. Distinct, after $3 \mathrm{~min}$.

(4) 0.000490 .0000140 .000039 over $50 \mathrm{hr}$. Invisible, adapt.

In experiment (3) the plate illumination was just sufficient to produce a distinct image on a Seed 30 plate after an exposure of three hours, while the illumination on the retina as viewed was three times as great, the source being just easily visible after resting the eye about three minutes in total darkness. In other words, an image on the retina just visible after partial adaptation to darkness would just produce an image on a photographic plate after an exposure of one hour. The retina fully adapted to darkness is still a thousand times more sensitive than this.

Rochester, N.Y., June.

P. G. Nutting.

\section{June Meteors.}

A PARAGRAPH referring to some brilliant meteors observed at Bristol on June 25 appeared in NATURE of July 2 (p. 464), and I am induced to send a few details of our June results, for they appear to me to exceed in importance and interest any obtained in any other month for a long period. There are a large number of double observations of the same objects, and I have been enabled to compute the real paths of fourteen, particulars of which are given in the subjoined table. They were all observed by Mr. S. A. Wilson and Mrs. Fiammetta Wilson (marked "W."), and some were recorded by Miss A. Grace Cook and some by myself. The very persevering and accurate observations by Mrs. Wilson and Miss Cook have been very successful in this branch of astronomy in the last few years.

\begin{tabular}{|c|c|c|c|c|c|c|c|}
\hline Nate $19 x_{4}$ & $\begin{array}{l}\text { G.M.T. } \\
\text { th. m. }\end{array}$ & Mag. & $\begin{array}{c}\text { Height } \\
\text { at } \\
\text { first, } \\
\text { miles }\end{array}$ & $\begin{array}{l}\text { Height } \\
\text { at } \\
\text { end, } \\
\text { miles }\end{array}$ & $\begin{array}{l}\text { Path } \\
\text { miles }\end{array}$ & $\begin{array}{l}\text { Velocity } \\
\text { per } \\
\text { second, } \\
\text { miles }\end{array}$ & $\underset{a}{\text { Radiant }} \delta$ \\
\hline June 3 & 1030 & 9 & $5^{1}$ & 48 & 160 & 25 & $2 \stackrel{8}{8} \mathrm{I}-2 \stackrel{0}{5}$ \\
\hline I5 & I I $\quad 4 \frac{1}{2}$ & $4^{-I}$ & 60 & $5^{2}$ & 26 & 19 & $260-22$ \\
\hline , & I I $8 \frac{1}{2}$ & 2 , & 87 & 62 & 68 & 35 & $279-13$ \\
\hline , & I I 32 & $6-4$ & 69 & 53 & 27 & 41 & $315+21$ \\
\hline 16 & I I $O$ & $2-1$ & 69 & 43 & 29 & 29 & $270+50$ \\
\hline $2 I$ & II 22 & $3-4$ & 72 & 48 & 37 & 37 & $293+10$ \\
\hline 25 & I0 $51 \frac{1}{2}$ & $>1$ & $4^{8}$ & 44 & I4 & 20 & $260-24$ \\
\hline , & I I $27 \frac{1}{2}$ & 9 & $5 \mathrm{I}$ & 25 & 45 & 30 & $342+39$ \\
\hline ", & II 46 & $5-4$ & 68 & 48 & 39 & 25 & $258+2$ \\
\hline , & I I $52 \frac{1}{2}$ & $1-4$ & 59 & 23 & 46 & 18 & $354+77$ \\
\hline , , & I I $57 \frac{1}{2}$ & 4 & 67 & 67 & $5^{2}$ & $5^{2}$ & $350-8$ \\
\hline 26 & II II $\frac{1}{2}$ & $4-2$ & 78 & 67 & I I & 25 & $260+70$ \\
\hline , & II $17 \frac{3}{4}$ & $4-2$ & 75 & 56 & 22 & 44 & $320+6 x$ \\
\hline 29 & I I 25 & I & 64 & 53 & I9 & 26 & $320+19$ \\
\hline
\end{tabular}

objects too faintly illuminated to be seen. At the suggestion of Dr. Mees, the writer, assisted by $\mathrm{Mr}$. Huse, has made some observations with measured illuminations giving comparative sensibilities of the human retina and an extra rapid photographic plate.

The source used was a sort of artificial moon consisting of a ro-candle Tungsten lamp in a metal box over the front of which were placed several layers of dense opal glass. The normal light flux from this surface measured equivalent to 8.6 metre candles. This intensity was further reduced by neutral filters transmitting $\mathrm{I} / 26$ of the light. This source was placed at one end of a $20 \mathrm{ft}$. tube (our plate resolving power NO. 2332, VOL. 93]
Observers

Meteor appeared over
W. and others

W. and W. F. D.

W. and W. F. D.

W. and W. F. D.

W. and F. Denning

W. and A. G. C.

W. and W. F. D.

W. and W. F. D.

W. and W. F. D.

W. and W. F. D.

W. and W. F. D.

W. and A. G. C.

W. and A. G. C.

W. and W. F. D.
The Wash to Durham

Alton to W. of Reading

Wilts to Ross

Tunbridge Wells to Dorking

Sea $34 \mathrm{~m}$. E. of Broadstairs

I2m. W. of Bristol to Usk [Harwich

$15 \mathrm{~m}$. W. Aldershot to Henley

Iom. S.W. Luton to $8 \mathrm{~m}$. S. E. Reading 4m. N.W. Salisbury to Axbridge S. of Bedford (nearly vertical) Halstead to Bishops Stortford [Hants Eng. Chan. 32m. S. of Christchurch,
Selsey Bill (nearly vertical)

Now that the most attractive and prolific season for meteoric work is at hand I trust that some readers of NATURE may be inclined to watch the sky and record the apparent paths of such meteors as may appear. They are usually unduly plentiful between the middle of July and middle of August, and the great Perseid shower can be favourably traced during nearly the whole of the period named. Davidson, director of the Meteoric Section of the British Astronomical Association, or to myself.

44 Egerton Road, Bristol, July 6 .
I2m. N.W. Chelmsford to $6 \mathrm{~m}$. N.W.

Any observations may be forwarded to the Rev. M. 